"Las opiniones vertidas en este artículo son responsabilidad del autor"

\title{
El problema del aborto
}

\author{
Sosa Trotti, Roberto A.
}

\section{$\underline{\text { Resumen }}$}

Se reflexiona en torno al aborto discrecional y cómo sus posturas antagónicas parten de un mismo punto de las conductas humanas. Se revisa en los ancestrales comportamientos humanos el abuso del poder patriarcal sobre los otros componentes sociales; luego, en continuidad histórica, el poder que dispone la mujer sobre el no nacido. Indiferenciado ambos, como procedimientos pragmático-utilitarios.

Se evidencia la grave dificultad de establecer en la vida prenatal un límite entre ser humano y "sub-humano". Se desmonta la dicotomía aborto libre o muerte de la mujer. Se fundamenta porqué hoy, el aborto, en la práctica, es libre, accesible y socialmente descriminalizado, por ende, el castigo no disuade. Por consiguiente, considerar su despenalización podría favorecer la reducción de la morbimortalidad de la mujer y, hasta recapacitar sobre la decisión. Se afirma qué las restricciones educativas, sociales y económicas que empujan al aborto deberían ser prioridades a resolver mucho más humanitarias que recetar "la solución" del aborto subsidiado por el Estado. Se observa que el plexo legal-constitucional argentino colisiona directamente con un "escape" a la legalización del aborto. Se enfatiza que atacar dogmatismos poco ayuda a comprender la complejidad del aborto. Una educación y ética del respeto es la posibilidad viable.

Palabras Clave: aborto voluntario, enfoques éticos, prevención, despenalización. Abstract

We examine about the polar differences on discretionary abortion, how could originate from the same point of human behavior and how harmful their extreme positions. Human behavior, since ancient times, abuse of patriarchal power over other social components are reviewed. Then, as historical continuity, the woman can apply its power over the unborn. Undifferentiated both as pragmatic-utilitarian procedures. It reflects on the known life of our prenatal emphasizing the difficulties in establishing net boundaries between a conscious human being and a "sub-human". Imposing dichotomies relating to abortion is removed. It is based on abortion today, in practice, is free, accessible and socially decriminalized therefore punishment does not deter. And considering no penalty could facilitate reducing mortality and morbidity generated and for women, to reconsider o reconsider the decision to abort. Analyzes because the educational, social and economic constraints that push abortion should be priorities to solve much more humanitarian than prescribed as the "solution" to abortion subsidized by the state. Argentine legal-constitutional framework indicating a direct collision with an "escape" to the legalization of abortion is discussed. It is emphasized that attacking patriarchal institutions dogmatism little help to understand the complexity of the abortion. Education and ethics of respect is viable possibility.

Keywords: voluntary abortion, ethical approaches, prevention, decriminalization. 


\section{Introducción}

El aborto inducido al ser problemática del quehacer médico es pertinente a una publicación médica.

Asimismo, es una cuestión dilemática y sensible. Y lo es, porque -a conciencia- se elimina a la descendencia en gestación, en oposición a la disposición de crear vida y defenderla. Por ello, quien lo restringe únicamente a la visión sanitaria elimina otras miradas tan humanas como imprescindibles.

El eje conductor de este artículo es reflexionar en torno al aborto voluntario a fin de ser participante en la construcción de una opinión sobre ello. En ello, se entiende a la lucha proaborto discrecional como una herramienta política que requiere una mirada cuidadosa. Esto hace insoslayable relacionarla con cuestiones de la sociedad humana y lo que esta produce.

Antes, es preciso dar nombre a aquello que origina el aborto voluntario sea un problema, dado que no se elimina algo cualquiera de una especie cualquiera; lo que se impide es el nacimiento de un individuo humano. Además, aquello que no tiene nombre es más fácil de no dar entidad, de omitir.

Este humano en sus primeros momentos de vida podrá hallarse en período de ser zigoto, mórula, gástrula, blastocisto, embrión o feto. Todos ellos, son nombres que señalan tiempos o edades que hemos atravesado cada persona antes de ser paridos. Por esto, con afán de integrar y respetando sus indudables características, prefiero llamarlo "humano prenatal". Luego, considerar qué simboliza el humano prenatal y qué acciones surgen en torno a su valor. En una visión se reconoce en aquel su dignidad intrínseca, por ello, una vida a ser protegida. En su antítesis, un mero cúmulo de células, que puede ser descartado; evidenciando que el derecho a la vida será dado por quien detente poder sobre esa vida. Así, se observa que grupos radicalizados propugnan al aborto como una praxis que permitiría a la mujer reivindicar sus libertades corporales humilladas por siglos; y su antagónico asevera que el poder se aplica para anular un niño donde hoy existe un embrión.

Somos humanos, cada convicción o rechazo emerge legítimamente de la propia trayectoria de vida. Con todo respeto a las certezas personales, cuando se escucha que abortar es "asesinar un niño", o por contraposición, se clama que "la iglesia encarna el dominio machista"; pregunto: pretender imponer doctrinas ¿no bloquea todo diálogo y comprensión del problema? ¿es forzoso entender al aborto, como dicotomía blanco/negro? ¿solo se es progresista propiciando el aborto legal y gratuito? ¿solo un devoto respeta al humano prenatal? ¿se percibe que para cada mujer, cada embarazo pueden ser situaciones

diferentes, ambivalentes, peligrosas? ¿se comprende que muchos, aun siendo no buscados, contaron con la oportunidad de participar de lo que existe y aún falta hacer?

\section{Concedo la vida, otorgo la muerte}

\section{Largo prontuario}

Al revisar las conductas humanas es dable considerar que las posiciones extremas respecto del aborto podrían originarse en un mismo punto. En su comprensión es preciso marcar algunos puntos clave: 


\section{Revista de la
Facultad de Medicina}

de la Universidad Nacional del Nordeste

- Los conflictos son inmanentes a la humanidad, de modo que la historia es el relato de sucesivas luchas que, en general, exponen la pésima gestión que desde el poder se ha hecho con aquellos que supone una interferencia, obstrucción o son inconvenientes (Bergman, 2009) .

- El predominio de los fuertes sobre los débiles impulsó el desarrollo de su correspondiente sistema socio-político, religioso y cultural que configurará las relaciones sociales en torno al poder y jerarquía; imponiéndose desde tiempos remotos, estrategias destinadas a mantener un sistema de dominación (Millet 1969)ii.

- Este pragmatismo“ político conforme fijaba los valores absolutos y a sus depositarios, descalificaba los derechos y potenciales de otros humanos. La denigración se ejercía sobre varios grupos, algunos, por ser un desposeído de todo: el sistema esclavista, otros por ser mujer, o por ser niño, o recién nacido. Los humanos degradados o "invisibilizados" estaban a libre disposición y arbitrio de quien detentaba algún poder, sea económico, político, religioso.

- Se configura así la visión Pragmática - Utilitaria del mundo *. Sin embargo, con el avance civilizatorio se racionaliza la "cosificación" del más débil en pos de su uso.

Desarrollar ampliamente el dominio patriarcal de milenios y entre sus consecuencias la condena a la mujer de servir y callar, excede a los fines este artículo. Solo se exponen algunos trazos para comprender las conexiones entre la lucha de reivindicación femenina y el aborto discrecional.

Desde el poder suelen justificarse las matanzas con el recurso de rotular como sub-humanos a cualquiera que sea interferencia. El exterminio de un grupo humano, típicamente, comienza privándole de estatus legal, excluyéndolo del mundo, como ocurría en campos de concentración, o, descalificando el valor moral e intelectual de la mujer en la Grecia de Sócrates; o, en la Roma arcaica, la potestad del Pater Familia para matar a sus hijos; o, permitirse eliminar pueblos originarios quitándole su valía humana. Hoy, naturalizar la anulación discrecional de vida humana, hereda el uso normal de aquel poder de hierro y fuego.

Otro ejemplo de descalificación, fue la reacción a la puja por el sufragio femenino. En 1931 el médico y diputado español Novoa Santos ${ }^{\text {iii }}$ decía: ¿Por qué hemos de conceder a la mujer los mismos derechos políticos que al hombre? ¿Son organismos igualmente capacitados?(...)La mujer es toda figura de emoción; (...)no es reflexión,(...)no es ponderación. (...) se haría del histerismo, ley. El histerismo es la propia estructura de la mujer. Esto es la mujer.

\footnotetext{
^ Pragmatismo en sentido de actitud y pensamiento que solo da paso a la utilidad y valor práctico de actos y cosas en desmedro de sentimientos humanitarios. Así mismo, la función de los objetos y la relación sujeto/objeto resulta de la necesidad de uso.

- Esta expresión no se refiere la practicidad utilitaria de médico y filósofo J. Locke (1632- 1704), quien si propiciaba respetar la voluntad individual sin que ninguno actúe en desmedro de los demás.
} 
Fueron anuladas y abusadas en cuanto al uso de su cuerpo; al que se lo circunscribió a la función de las labores de la casa, la procreación, el cuidado de los hijos y a la subordinación legal y económica de la figura masculina. Refrendándolo, las Naciones Unidas (1993), dice: "el ejercicio de la fuerza y el poder contra la dignidad humana de las mujeres [es] una manifestación de las relaciones de poder históricamente desiguales entre mujeres y hombres". iv También, en el año 2000, Juan Pablo II pide perdón por los errores cometidos por su Iglesia en detrimento de las minorías y las mujeres. ${ }^{\vee}$

Las luchas de la emancipación femenina son largas y justificadas. En general, las sociedades occidentales actuales, son congruentes con aquellas premisas que propugnan igual valía respecto al potencial como personas, a su voluntad o no a la maternidad, a los méritos laborales, remunerativos o políticos. Con idéntica importancia, sumemos la igualdad en dignidad y atribución de derechos a todos los que también fueron ultrajados y postergados por un sistema sexista de dominio patriarcal.

\section{"Que animal tan feo es el mono y cuanto se nos parece" Cicerón}

Si reconocemos la tiranía y a su reactiva lucha reivindicatoria, del mismo modo, señalemos que cuando el oprimido logra liberarse y alcanzar un efectivo empoderamiento, puede ocurrir que en su reacción pragmática extrema, corra la suerte de ser igual o peor a quienes fueron sus opresores. Esa semejanza entre el opresor y el oprimido liberado puede ejecutarse tanto en sus argumentos como en actos violentos, aplicando procedimientos similares a los que fueron sometidos. No debe asombrar que los ahora aniquilados sean igualmente "invisibilizados" por sus ejecutores, tal como ocurre cuando se sub-humaniza al humano prenatal, calificándolo próximo a la cualidad de cosas. Así, las luchas de reivindicación van sincrónicas con la disposición discrecional de embriones humanos. Los grafitis de combate anti patriarcal lo dicen: iNI MACHO, NI FACHOi-iABORTO LEGAL YA!

\section{Víctimas más víctimas}

Todo conflicto que se asemeje a la guerra parece necesitar un enemigo a demoler a fin de reafirmar la propia determinación. Este concepto suma para explicar que la lucha por la legalización del aborto trata especialmente de quebrar el poder patriarcal sexista -meta no siempre explícita-. Pero en toda guerra, las verdaderas víctimas son los inocentes sin culpa ni responsabilidad. Son inocentes tanto, las mujeres que por causas -casi siempre preveniblesson empujadas a un embarazo, como así también es inocente el humano prenatal. Sin embargo, la violencia del aborto no solo cae sobre el embrión sino también sobre la mujer cuando, en incontables veces, ella es presionada al aborto`(Klein, 2005) ${ }^{\text {vi }}$. Pero, como decía

\footnotetext{
- De "El Aborto, ver, escuchar y sentir", del suscripto: Decidir abortar ¿es una libre elección? La mujer casi nunca toma esta decisión en una libertad sin condicionamientos. Existen presiones y estas son veladas formas de violencia de género: mandato (real o imaginario) de los padres, de la familia o la situación de pareja: por imposición o disolución de ésta, coacción del trabajo, ("mobbing maternal"), dificultades económicas, de la profesión o el estudio, de la pareja que la fuerza sexualmente en privado, etc. Estas presiones son actos de violencia que se practican contra la mujer. Así como existe violencia al embarazarse, existe también violencia para abortar.
} 


\section{Revista de la
Facultad de Medicina}

de la Universidad Nacional del Nordeste

antes, somete quien detenta poder; y cuando de aborto se trata, en el último eslabón, la violencia se ejerce sobre el que inevitablemente perece: el humano prenatal.

\section{La continuidad histórica}

En el dilema entre la mujer y la eliminación de una vida, algunos resolvieron por la eliminación. La permisión del aborto en los países centrales - de alta población envejecida y un largo pragmatismo imperialista- admitió que el humano prenatal, de facto, carezca de reconocimiento, estatus moral y protección, bajo el argumento que el potencial de convertirse en persona no da a un individuo el derecho a la vida disfrutado por las personas propiamente dichas. (Selgelid, 2004) ${ }^{\text {vii }}$ Esta percepción estimula comparaciones del tipo una semilla no es un árbol. Pero ¿quién dictamina el estatus jurídico y significado de personas "propiamente dichas"? ¿existe una definitiva convención mundial? Aseverar: "simple potencial no implica derecho" es un dogma o, al menos es una opinión dicha desde algún lugar de poder y que omite otras miradas.

Vale mencionar la entrevista realizada por Arcadi Espada a Fernando Savater ${ }^{\text {viii: }}$

A.E: ¿Qué es, exactamente, lo que nos hace humanos?

F. S: La capacidad simbólica.

A.E: Y un bebé, ¿qué capacidad simbólica tiene?

F. S: La que va a tener. Aristóteles, cuando hablaba de la potencia, estaba refiriéndose a eso.

AE: Si lo humano fuese lo que puede ser humano, hay serios problemas. Por ejemplo [para la legalización del] aborto, no hay plazos que valgan.

Sin embargo, la posición proaborto reniega la protección del humano no nacido al no poseer la sensibilidad, autonomía, ni consciencia propia, ni autoconciencia en el tiempo (Tapia, 2011) $)^{\text {ix }}$ Así, al no cumplir con estos requisitos, no pueden ser personas, solo un manojo de células sin significado.

\section{“Quien ve crecer las cosas desde el inicio, tendrá una mejor visión de ellas" Aristóteles}

El conocimiento actual de las capacidades embrio-fetales describe que la percepción fetal, dependiente de la mielinización, y ocurre aproximadamente desde las semanas 20-23 del embarazo (Di Pietro, 2010) ${ }^{x},(B e l l i e n i, ~ 2012)^{x i}$ Ahora bien, ¿y si en su devenir la ciencia descubre que la corteza cerebral sí recibe impulsos tempranos de sensibilidad, o que el dolor pudiera tener otras raíces diferentes, o ¿si se hallara que el humano prenatal tuviera mayor conciencia de lo que creemos hoy?

En otra dimensión del conocimiento humano -aquella de la observación de la gente corriente- a menudo se acepta la capacidad de percepción del embrión. En igual sentido se siguen sumando artículos científicos que informan sobre verificaciones de la "memoria intrauterina" (Garcia Heller, 2007) xii xiii. Deberíamos tener un mínimo de humildad y reconocer, que en no pocas ocasiones, lo que el conocimiento común afirma desde hace siglos, hoy día y luego de rigurosas y costosas investigaciones se obtienen las evidencias científicas que validan aquel "saber popular". "Si lo desconocido es tanto o más grande que lo conocido, es menester abstenerse de querer reducirlo a leyes" (Barylko, 1992) ${ }^{\text {xiv }}$ 


\section{Revista de la
Facultad de Medicina}

de la Universidad Nacional del Nordeste

Pero, si los países más desarrollados - los que a su vez han legalizado el aborto- son quienes poseen los recursos para comprobar aquello que el humano prenatal percibe y tiene conciencia, un hallazgo reivindicatorio, podría acaecer como un dato científico políticamente complicado.

\section{Trayectoria humana ¿con punto de corte?}

El cerebro humano es la estructura más compleja del universo (Manes y Niro, 2014) ${ }^{\mathrm{xv}}$. Esto incluye afirmar que la humanización es un proceso que ocurre a lo largo de la vida y con la crianza junto a otros humanos, en la cual el lenguaje, es fundamental. Pero pregunto: ¿cuándo se adquiere, en el devenir humano, la plena capacidad de conciencia y raciocinio que se exigen para alcanzar valía moral, la dignidad y el derecho a la vida? Entonces, ¿por qué no requerir otros rasgos propiamente humanos?, por ejemplo: la capacidad de autopercibirnos como un ser que transcurre en el tiempo y en lo inconmensurable del universo; o, ser concientes de los cambios cualitativos externos que ocurren en el transcurrir de la historia de toda la humanidad; o, la consciencia de la valía de otros seres humanos; o ser capaz de asumir que toda elección, acción u omisión tiene consecuencias y que se es responsable de ello? ¿Cuándo se adquieren plenamente estas capacidades? ¿Cuándo se hace posible un mínimo asomo de pensamiento característicamente humano? ¿Al madurar el desarrollo neurológico prenatal? o ¿con la madurez del cerebro y el control cognitivo luego de los 21 años? (Manes y Niro, 2014), (Rosler, 2014) ¿vi ¿Y hasta entonces qué? ¿Todavía son cosas/entes anulables?

Por una convención se le adscribe de dignidad y derecho a la vida cuando un ser humano ha nacido. Ahora, consideremos: “Un niño que ha nacido en la 25 semana de gestación estará obligadamente en una incubadora, menos desarrollado, en peores condiciones y no más independiente que un feto normal que todavía se halla dentro de su madre en su 37으 semana de gestación. ¿Qué diferencia hay que justifique asignar a aquel humano nacido a las 25으 semanas todos los derechos de una persona, pero no a este feto de 37 semanas todavía in útero? ¿Qué diferencia existe para justificar interrumpir la vida al humano prenatal cuando estaría mal matar al niño ya nacido? (Wertheimer, 1983) ${ }^{\text {xvii }}$.

"Deshilar" semanas de gestación es caer en el error de pretender un punto, en el que el

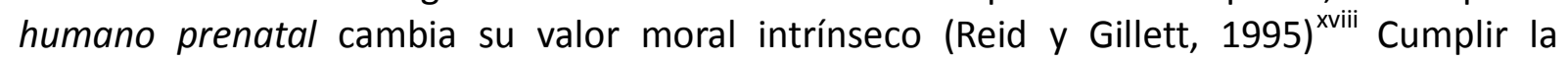
convención "ser nacido" para que solo entonces exista dignidad y el derecho a la vida, parece un imposición muy endeble.

\section{¿Dignidad vs. Autonomía?}

En 1993, el Tribunal Constitucional Alemán afirmó que "desde el principio del embarazo pertenece a la vida humana no nacida el derecho a la vida, en base a su dignidad humana"• (Stith, 1994) $^{\text {xix }}$. Esta misma institución, al igual que la ya citada Naciones Unidas (1993),

\footnotetext{
- Así mismo, este tribunal, indicaba que el aborto no debe ser contenido en las prestaciones de un plan nacional de salud, porque haría parecer normal ese "acto de matar". Además, aceptó que el castigo penal pueda no ser el único, ni la más efectiva protección al no nacido. Vale referir que el mismo no decide por preceptos religiosos.
} 


\section{Revista de la
Facultad de Medicina}

de la Universidad Nacional del Nordeste

eligen la palabra dignidad, este término indica una valoración independientemente de si los otros ven o no ven aquello que resguarda su respeto. Así este concepto sustenta que la dignidad y respeto es inherente a un embrión aún antes del valor que los progenitores pudieran concederle."

Sin embargo, Maklin (2003) ${ }^{\mathrm{xx}}$ critica lo vago e impráctico del término "dignidad", y que no es más que respeto a la autonomía sustentada en la capacidad de acción racional del hombre: tomar decisiones y proceder en consecuencia. Así, propone eliminarlo sin pérdida de contenido.

Aunque el principio de autonomía parece un concepto operacional y útil, pregunto: ¿qué niño de primer infancia e incluso tantos humanos -en cualquier tiempo de su vida-, no se hallan supeditados a otros y se bastan absolutamente a sí mismos; y más aún, un individuo, al menos temporalmente, inhábil en su razón y capacidad de actuación?

En cuanto, al embrión humano, hoy ¿se puede negar que sea una realidad concreta, definitivamente humana y diferente de sus progenitores? ¿̇o, que posea la autonomía y determinación genética para seguir viviendo y comandar por sí mismo su propia formación? Coincidiendo con Pyrrho (2009) ${ }^{\mathrm{xxi}}$ : la dignidad humana se construye con la relación y el reconocimiento del Otro, equivalente a mí, aun cuando todavía no sea igualmente autónomo.

Este concepto es pertinente al presente artículo: se protege la vida del no nacido, porque al ser un humano, se le respeta su derecho a la vida.

En la antítesis se afirma que solo la gestante determina el estatus moral fetal, pudiendo sentirlo como un nuevo miembro de su familia destinatario de afecto, cuidado y crianza o, todo lo contrario.

\section{...Desentraño la esencia de mi propia existencia. (E. Blázquez, 1995)}

En este debate planetario, el feto parece ser un área gris en el concepto de persona. Si es claramente una persona, ¿por qué cuesta tanto a sus defensores demostrar este hecho claro a los liberales? Si el feto claramente no es persona, ¿por qué cuesta tanto demostrar este hecho claro a sus opositores? ¿No es hora de aceptar que es una cuestión probablemente sin respuesta...? (Selgelid 2004). Klein (2005) agrega: Si se puede demostrar con igual rigor que se es y no se es persona desde la concepción, es porque ese interrogante escapa a las posibilidades del conocimiento, de la lógica y de la ciencia.

\footnotetext{
* E. Kant en "Metafísica de las costumbres": la dignidad significa que la persona humana no tiene precio, sino dignidad: "Aquello que constituye la condición para que algo sea un fin en sí mismo, no tiene mero valor relativo o precio, sino un valor intrínseco". En "Principios Metafísicos del Derecho": Los seres cuya existencia no descansa en nuestra voluntad, sino en la naturaleza, tienen, cuando se trata de seres irracionales, un valor relativo, como medios, y por eso se llaman cosas; en cambio, los seres racionales se llaman personas porque su naturaleza los distingue como fines en sí mismos, como algo que no puede ser usado como medio y, por tanto, limita, toda arbitrariedad y es objeto de respeto.

http://www.philosophia.cl/biblioteca/Kant/fundamentacion\%20de\%20la\%20metafisica\%20de\%20las\%20costum bres.pdf
} 
Selgelid replantea: Estaríamos equivocados al pensar que cualquier individuo que satisfaga nuestra definición elegida de "persona" - sea cual sea-posee, por eso, derecho a la vida. Y sigue: El mero hecho que un individuo, por convención, sea considerado persona no [automatiza] que tenga derecho a la vida. En consecuencia, quien tenga el poder de seleccionar por sostener o no ese derecho, será el que disponga de esa vida.

Este concepto, quizás, ayuda a comprender que en el pensamiento pragmático-utilitario antes mencionado existe una inmanente afirmación que, aunque no la pronuncien, dice así: ...no existen seres humanos que tengan un derecho intrínseco a la vida, ya que tales derechos son simplemente conferidos por quienes tienen el poder para conferir, y pueden ser retirados por aquellos que tienen el poder de anularlos (Gillon, 1991).

Ejemplos abundan.

\section{LA DICOTOMÍA MATAR O MORIR}

Una sociedad siempre genera multiplicidad ideológica, pero no siempre existe una cultura de aceptación de esa diversidad. La nuestra es una de ellas y algunos gobiernos lo han aprovechado para usar estrategias del tipo nosotros o el caos. Provocan antagonismos, brechas y dicotomías de polarización (Bergman, 2009) que intentan imponer enfoques del tipo blanco/negro, bueno/malo. Sin embargo, todo ocurre en un contexto complejo y una diversidad ilimitada donde existe el blanco, el negro y entre ellos, todos los colores.

\section{Esclavos del "blanco o negro"}

El eslogan que corean los interesados en legalizar el aborto discrecional, es: "Educación para decidir, Anticonceptivos para no abortar y Aborto libre para no morir".

Este lema usa la técnica agit-prop ${ }^{x x i i}$ : propaganda de agitación, en la que se especulan con medias verdades y consignas duras para movilizar la opinión pública. No obstante, con el primer componente: "Educación para decidir", debo coincidir y celebrar junto a quien la propone.

De "Anticoncepción para no abortar", reafirmo primero: con una adecuada anticoncepción se reduce drásticamente la probabilidad de una gestación. Esto es prevenir, que no significa anular la posibilidad al punto cero, "sin riesgos" es una ilusión infantil. Una persona informada -al menos por su madre- sabe que en nuestra ineludible condición biológica, la fusión sexual está "diseñada y programada" para engendrar la vida de un individuo humano. Sabemos que aun con anticoncepción, el embarazo es un incidente poco probable, pero nunca un accidente imprevisto. Pero, ante un embarazo incidental, la consigna: "anticoncepción para no abortar" presiona al aborto sin otra opción. Se empuja como único escape al aborto, sin dar un tiempo en silencio para una profunda reflexión. Así, si sucede el embarazo, buscado o no, y ya existe la posibilidad concreta de un hijo, pese a la repercusión inicial, en muchas ocasiones, el amor sobreviene y el hijo es bienvenido por ésta mujer o por otra persona (para lo que debería existir una adopción agilizada). Estas conductas y afectos, afortunadamente, dan un inmenso valor y sentido a nuestra humanidad.

Con el tercer -y más famoso- componente del eslogan: "Aborto libre para no morir", se alcanza la máxima explosión de la dicotomía. Ahora el argumento insignia proabortista fuerza un enfrentamiento a muerte entre el derecho a la vida del concebido contra la 


\section{Ravista de la}

de la Universidad Nacional del Nordeste

disposición liberal de la mujer sobre su cuerpo. Se miente sin eufemismos que sin aborto discrecional, la mujer que aborte, ineludiblemente, va a la muerte: el pensamiento único (G. Orwell, novela 1984, publ. en 1949).

\section{LO QUE OCURRE}

\section{Aborto sin huellas}

Se ha dicho mucho sobre la inaccesibilidad y obstáculos para que una mujer pueda acudir al

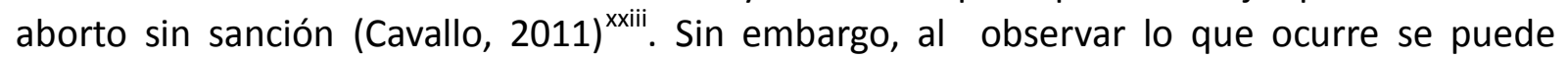
afirmar con Mainetti (2007) ${ }^{\text {xxiv }}$ que la ilegalidad no parece ser el mayor factor de peso a la hora de decidir abortar.

Abortar discrecionalmente, -en la práctica de hoy-, no solo es libre y accesible, sino que también está socialmente descriminalizado. Esta descriminalización existe dado que la reacción social ante el acto, es de tolerancia o indiferencia ${ }^{\mathrm{xxv}}$; y esto no es la despenalización formal del acto.

Hoy, el aborto inducido socialmente descriminalizado, se sostiene en varios puntos de apoyo: A)- En que el que asiste prefiere no enjuiciar y omite la denuncia.

B) - En la Ley 26. $529^{\text {xxvi }}$ que exige el deber de confidencialidad.*

C) - En la jurisprudencia ya existente desde el año 1966 con el caso de Natividad Frías. $^{\text {xxvii } x x \text { viii } x x i x}$

D) - En la creencia social que es una práctica muy frecuente, $66 \%$ según CEDES-UNFPA (2006) ${ }^{x x x}$ aunque esta creencia no implica la aprobación del aborto por cualquier razón * (Rouviere, 2010) $)^{x x x}$.

Resumiendo, ¿alguien recuerda alguna mujer en prisión por haberse practicado un aborto?

Para que ocurra, participa muy especialmente el uso de un medicamento: el misoprostol (aplicación similar a un óvulo vaginal). Su uso inicia en la década del 90 y reduce rotundamente las complicaciones de otros tiempos. Aunque su venta formal es "bajo receta", y se deba andar más de una farmacia, este fármaco es accesible y a un precio apenas mayor que un kilogramo de yerba mate, lo que permite que lo usen la mayoría de las mujeres que se realiza un aborto discrecional.

La facilidad de uso del misoprostol ha vuelto obsolescente las colocaciones de sondas, agujas, tallos vegetales, curetas y otros elementos contaminados involucrados desde siempre en "carnicerías fatales". Hoy día, el completo asesoramiento para la auto-administración de misoprostol y prevención de complicaciones está tan difundido como la telefonía celular o internet. Se los halla con facilidad en Línea Aborto (011)-1566647070.

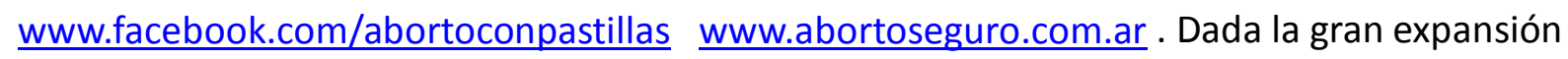

\footnotetext{
* Aunque el deber de confidencialidad pudiera colisionar con el artículo 156 del Código Penal: el de "causa justa" para relevar el deber de confidencialidad o secreto médico

- Encuesta R. Rouvier sobre la legalización del aborto Casi la mitad de los ciudadanos que contestaron esta encuesta considera que no debería legalizarse el aborto. Hay un 35,2\% que dice que debería legalizarse hasta las 12 semanas de embarazo. Y para el 8\% debería habilitarse la interrupción para cualquier momento del embarazo.
} 
de estos sistemas, parece razonable que, si alguien no puede acceder a ellos, es menos probable que acceda a los sistemas formales de salud, por más legal que sea el aborto.

La fácil auto-administración de misoprostol, entre otros importantes factores, participa en la lenta pero sostenida reducción del componente aborto de las tasas de Mortalidad Materna sin la ejecución efectuada por los recursos materiales y humanos del Estado.

\section{Las cifras del aborto voluntario}

Un argumento para impulsar a las naciones a legalizar el aborto es la cantidad de abortos intencionales. Por ello, sus cifras son muy relevantes. En la Argentina tuvo mucha difusión el informe de la ONG Human Rights basado en Estimación de la magnitud del aborto inducido en la Argentina de Pantelides y Mario (2009) ${ }^{\text {xxii }}$. Allí afirmaban que se estarían realizando alrededor de 460.000 abortos al año, estimados con el método descripto por Singh y Wulf $(1994)^{\bullet}$. Esta metodología es cuestionable de alta subjetividad, dado que se basa en opiniones de informantes clave extraídos de un sector sesgado y parcializado de la sociedad; son estos: las activistas femeninas, quienes atienden a las que buscan abortar y los efectores sanitarios que asisten a las que se complican.

Por su parte, Elard Koch (2012) ${ }^{\text {xxiii }}$ ha calculado la cantidad de abortos en la Argentina de la siguiente manera: a partir de estadísticas vitales oficiales del Ministerio de Salud argentino y a través del Modelo de Embarazos Esperados sustentado en las probabilidades biológicas de una concepción viable publicadas por Wilcox en al.(1995) ${ }^{\text {xxxiv** }}$. Como conclusión de este

estudio, la cifra de abortos para la Argentina del año 2007 fue calculada en aproximadamente 47.636 casos, valor 9,8 menor que el propuesto por Pantelides. La estimación mucho más alta de abortos inducidos del método Singh y Wulf también se observó en Colombia y México ${ }^{\mathrm{xxxv}}$, donde se amplificó en diez veces la cifra de abortos provocados (La Prensa, 2011). ${ }^{\text {xxxi }}$ Estas drásticas diferencias llaman a la cautela, dado que este tipo de informes alarman a la opinión pública y las decisiones institucionales. Algo

\footnotetext{
- Descripto por Pantelides y Mario, 2009. Sus fuentes provienen de las estadísticas de egresos hospitalarios por complicaciones de aborto, año 2000, más una encuesta a informantes clave. Luego aplica un factor de multiplicación calculado como la media ponderada por estrato socioeconómico -pobres/ no pobres-. A los informantes clave se pidió opinión sobre la frecuencia de la práctica de abortos, las complicaciones asociadas, los proveedores de aborto y método de cada uno de ellos, la proporción de abortos complicados que requieren internación en hospital público. Se obtiene así el coeficiente: 6,80. Se lo multiplicó por la cifra de egresos hospitalarios por aborto, dando 460.000 abortos/año.
}

\footnotetext{
* Partiendo de datos como la tasa global de fecundidad y la población femenina en edad fértil, estimó el número de embarazos que ocurren cada año en la Argentina. Así conocer el total de embarazos esperados, la proporción de los que pronto se interrumpen espontáneamente (imperceptibles y diagnosticados). Los embarazos viables se divide en tres grupos: nacidos vivos, definidos en las estadísticas vitales; las muertes fetales (también hay registro fiable); y el grupo correspondiente a los abortos inducidos, calculado como el remanente faltante.
} 
similar ocurrió en USA (1968) en la campaña para legalizar el aborto organizada por B. Nathanson: "He trabajado con ahínco por el aborto legal, asequible y a la carta". Luego confesó, que entre sus estrategias, había falseado el número de muertes por aborto. ${ }^{\text {xxvii xxxviii }}$

\section{Sumario de Intenciones}

En la puja proaborto libre y gratuito existen intenciones explícitas y otras a explicitar: 10- Sanitarias: reducir las muertes por aborto provocado que suman al total de la mortalidad materna, especialmente en las clases desfavorecidas.

2o- Ideológicas: Aborto subsidiado por el Estado a todo pedido discrecional, como una inalienable libertad de disponer del propio cuerpo. Afirman que el aborto se castiga para controlar la independencia y la sexualidad de las mujeres. La doctrina se torna patente en la acusación que hace el feminismo de Uruguay, donde ya existe la legalización del aborto. Dicen: “...esta ley se hizo desde un imperativo de tutelaje y control sanitario de las decisiones de las mujeres, pero no desde la óptica del derecho de la mujer a decidir sobre su cuerpo..." (Abracinskas, 2013) ${ }^{\text {xxix }}$.

3a - Política (en sentido amplio): no menos importante en la lucha radicalizada por el aborto legal, es lograr asestar una emblemática derrota al poder patriarcal, materializado, entre otras iglesias, por el catolicismo. El enfático lema que lo evidencia es: "Saquen sus rosarios de nuestros ovarios" entre otros gestos aún más provocadores. ¿Es razonable o necesario enrolarse en esta beligerancia?

\section{¿Abortar para evitar la muerte?}

¿Estamos muy seguros que legalizar, sin más, evitaría la muerte? Al mismo tiempo, debemos tomar muy en cuenta la gravedad de la muerte de cada gestante. Con la información disponible (fuente: Dirección de Estadísticas e Información de Salud [DEIS] xl xli y Observatorio de Femicidios en Argentina) ${ }^{x \text { lii }}$ y sin ignorar lo muy cuestionadas que son estas cifras, en el Cuadro 1 se muestran los últimos años.

Las estadísticas Argentinas no distinguen abortos espontáneos de provocados, ni embarazo extrauterino. En los seis años del período 2008-2013 fueron rotuladas "Aborto" un número de 373 gestantes fallecidas. Muertes que siempre son conmoción, dolor y un compromiso para reducirlas.

Para evitar las muertes de gestantes veamos más: el Instituto Guttmacher (2012) $)^{\text {xliii }}$, indica que las mujeres que abortan en Estados Unidos aseguran haber sido víctimas de violencia física o sexual por su pareja con más frecuencia que el promedio nacional. En atención a ello, es pertinente relacionar violencia de género con aborto voluntario. Una reciente revisión 


CUADRO 1: Nacimientos, Muerte Materna gral., muertes por aborto y Femicidios. Rep. Argentina 2007-2013
\begin{tabular}{|c|c|c|c|c|c|c|}
\hline AÑO & $\begin{array}{c}\text { N}^{\circ} \\
\text { NACIMIENTOS }\end{array}$ & $\begin{array}{c}\text { N } \text { MUERTES } \\
\text { MATERNAS }\end{array}$ & $\begin{array}{c}\text { TASA } \\
\text { Mort Materna }\end{array}$ & $\begin{array}{c}\text { N }^{\circ} \text { muertes por } \\
\text { ABORTO }\end{array}$ & $\begin{array}{c}\% \text { Mort Mat } \\
\text { por Aborto }\end{array}$ & $\begin{array}{c}\text { N }^{0} \text { Mujeres } \\
\text { Asesinadas por } \\
\text { Violencia de } \\
\text { género }\end{array}$ \\
\hline 2007 & 700.929 & 306 & 4,4 & 74 & $24 \%$ & ¿? \\
\hline 2008 & 746.460 & 296 & 4 & 62 & $20,94 \%$ & 208 \\
\hline 2009 & 745.336 & 410 & 5,5 & 87 & $21,20 \%$ & 231 \\
\hline 2010 & 756.176 & 331 & 4,4 & 68 & $20,54 \%$ & 260 \\
\hline 2011 & 758.042 & 302 & 4 & 73 & $24,17 \%$ & 283 \\
\hline 2012 & 738.318 & 258 & 3,5 & 33 & $12,8 \%$ & 255 \\
\hline 2013 & 754.603 & 245 & 3,2 & 50 & $20,4 \%$ & 295 \\
\hline
\end{tabular}

sistemática con meta-análisis encontró que la violencia perpetrada por la pareja, también es un factor asociado al aborto voluntario, incluso repetitivo y oculto (Hall 2014) ${ }^{\text {xliv }}$. La Argentina da cuenta que en el $42 \%$ de las mujeres asesinadas, el autor fue su pareja (Collado Peña 2005) ${ }^{\mathrm{xlv}}$. En el período 2008-2014 asesinaron 1.808 mujeres por violencia de género. Shadigian (2005) ${ }^{x \mid v i}$ afirma que el homicidio es la principal causa de muerte asociada al embarazo, y en las adolescentes tres veces más que en las adultas, por lo general, por machismo criminal. En consecuencia, los equipos de salud deben entender que la detección de la violencia de pareja es un componente esencial de la atención de la embarazada.

Cuando alguien plantea "Aborto para evitar la muerte" ¿Seguro que la legalización, sin más, evitaría la muerte de mujeres en relación a su gestación?

\section{El amor por delante}

Existe quien afirma que el "derecho a la vida" puede ser usado a favor del aborto legal. En esta afirmación se dice que en el aborto discrecional solo se trata de poner el amor por delante, porque, seguramente, a ese inocente le espera un pésimo porvenir. Dicho de otro modo: "si no lo aborta antes de nacer, lo abortará después" arrojándolo a una niñez abandonada y luego será un delincuente. Si bien se debe prestar atención a esta razón pues evidencia inquietud por la vida humana, también es muy débil cuando:

1- iguales motivos para abortar son argüidos para enmascarar otras razones menos benefactoras.

2- asegurar esto es imponer a aquel humano prenatal la absoluta garantía de un futuro nefasto.

¿No es mejor trabajar sobre su realidad a fin de emerger de la pobreza y sus consecuencias?

Contra el aborto estamos todos. "Pepe" Mujica

En el año 2002 la Asociación de Obstetras de Uruguay tomó el desafío de remediar la alta mortalidad por aborto clandestino creando un dispositivo médico único. Resguardados en el derecho a informar, explicaron a las mujeres con intención irrevocable de abortar cómo 
hacerlo de manera segura. La clave fue el misoprostol. Mientras se generalizaba su uso y desaparecían las clínicas abortivas encubiertas, el 2008 fue el primer año sin ninguna muerte materna por aborto clandestino en Uruguay, resultado que se mantuvo casi sin alteraciones. ${ }^{x}$ vii Desde entonces se sumó el acceso universal a métodos anticonceptivos y la Mortalidad Materna cae marcadamente. En Diciembre de 2013, Uruguay legaliza el aborto. Su presidente fue enfático: "creo que nadie puede estar a favor del aborto como una cuestión de principios"... "contra el aborto estamos todos"xlviii. Aunque aseguró que despenalizar el aborto es "mejor que prohibirlo". No obstante, el mismo Mujica (2013) xlix confiesa haber fracasado en educación. Su Ministerio de Salud informó que en el primer año se realizaron 6.676 interrupciones voluntarias del embarazo. La población uruguaya en 2013 fue de 3,4 millones, el cálculo aritmético para la población Argentina, resultaría en 81.486. Aquel ministerio también afirmó algo importante: “En Uruguay están dadas todas las condiciones y la seguridad para que las mujeres tengan confianza y acceso al sistema de salud, para concurrir y realizarlo de manera legal."

\section{Chile por la educación y el embarazo seguro}

En la reducción de la Mortalidad Materna, Chile tiene uno de los índices más bajos de Latinoamérica sin haber legalizado la prestación del aborto por el Estado. ${ }^{\text {li }}$ Koch, (2010) ${ }^{\text {lii }}$ mostró que la prevención para tener "embarazos seguros" ha sido el camino con se ha logrado reducir la mortalidad materna, y no la promoción del aborto. En Chile "la razón de mortalidad materna se redujo de 275 por cien mil nacidos vivos en 1960, a 18,7 por 100.000 nacidos vivos en el año 2000, la mayor reducción observada en países de Latinoamérica". "El caso chileno es un ejemplo mundial porque nuestra mortalidad por aborto es mínima, similar a la de los países desarrollados. Incluso, mucho menor comparando con algunos países donde esta práctica es legal". Acota Koch "Tras analizar la experiencia chilena en 50 años concluimos que la educación juega un rol fundamental para reducir la mortalidad materna. Una mejor formación de la mujer permite el uso más adecuado de los servicios de salud materna disponibles, y su mayor instrucción se asocia con el ingreso al mercado laboral, lo que retrasa el embarazo. Además, la mujer desarrolla su autonomía y autocuidado mediante el uso eficiente de métodos de planificación familiar, lo que disminuye embarazos no intencionados y, en consecuencia, los abortos". Donoso y Oyarzún (2003) liii agregan: [en Chile] es posible inferir que el Programa Nacional de Planificación Familiar y la conciencia de la población hacia una sexualidad responsable se reflejen en la [menor] muerte por aborto. Señalan también que la población incorporó el misoprostol como método abortivo de autoprescripción; (...) que podría ser también un factor importante en la reducción de las muertes maternas por aborto ilegal.

\section{Siempre reflexionar}

Esta información indica que -en la experiencia de un país muy cercano al nuestro- es posible disminuir las muertes de mujeres sin ceñirse a que la solución es legalizar el aborto. Suman otras razones a esta afirmación: frecuentemente los abortos en malas condiciones ocurre en situaciones socioeconómicas y culturales de marginación y escasez. La 
antropóloga Mainetti (2007) cuando menciona que la ilegalidad no es lo más importante a la hora de decidir abortar, agrega:

(..) Vivir en regiones rurales o alejadas o aisladas, el analfabetismo, la pobreza, el desconocimiento y la ausencia de información sanitaria hacen que se recurra a soluciones alcanzables. Es decir, el recurso "casero", porque en su sentir, el hospital se les representa como algo inaccesible y no solo desde lo geográfico y lo económico. Muchas veces las largas e infructuosas esperas, el temor, la sensación de verse abrumado por palabras que no comprenden, análisis, gestiones incomprensibles y trámites complicados. También pesa en este grupo humano la desconfianza que genera ese otro mundo, ajeno al propio percibido en la institución sanitaria. El médico indiferente y distante en su rol hegemónico centrado en un sistema científico alejan la posibilidad real y concreta de recurrir a hospital; en cambio, la vecina o la curandera cercana a su casa, sí forman parte de lo propio, del sentido de pertenencia y a lo que por cercanía y hábito, entregan su confianza. Legalizar el aborto en las condiciones existentes, tanto para vivir como para morir, solo mantendrá afuera, -a aquellas mujeres- tanto a servicios de salud, como al aborto gratuito.

Sigue Mainetti: Más allá de las posturas con respecto al aborto provocado, no es tan evidente que éste aparezca como "la solución" al problema, sino como la consecuencia de muchos otros. Un camino más largo y laborioso pero más respetuoso de los derechos de cada ser humano [en cualquier etapa de su vida], será trabajar para eliminar los motivos que llevan a realizarlo.

¿Dónde deben aplicarse los mayores esfuerzos de protección al más débil? ¿en la legalización del aborto gratis "a la carta"? O ¿en el desarrollo social, educativo, en prevención de los daños asociados al género, pobreza o lejanía, en todas las personas y lugares donde aún falta?

Ya existen valiosos programas y manuales para acciones que se enuncian gratuitas, pero al no funcionar adecuadamente persisten el aborto, tanto como aquellas otras causas de daño y muerte. Las leyes "solas" no solucionan problemas, sí los actos respaldados en leyes cuando poseen metas primordiales que intervienen en los determinantes sociales y estructurales: garantizar el alcance equitativo a cada rincón de una educación-capacitación para la vida en sentido amplio, la autovaloración y el respeto al Otro, planificación familiar asesorada y de alcance universal. Y un desafío al sistema sanitario: un equipo de salud con personas comprometidas con su misión, co-responsables con sus pacientes, y hospitales francamente amigables con sus destinatarios.

\section{Aborto, Leyes, Derechos y Estado. ¿La ley gobierna al poder?}

Aunque el aborto está penalizado y la Constitución Nacional y su plexo legal protege al niño desde su concepción, no hay ley que disuada a una mujer decidida, ni Códigos que anulen su 
poder para hacerlo; porque el procedimiento-como se explicó antes- es accesible e íntimo. En otros términos: no tiene el Derecho pero tiene el poder ${ }^{\bullet}$.

\section{¿Qué dice y qué no dice la Convención?}

En la Declaración de los Derechos del Niño (Ginebra, 1924), en Asamblea General ONU (1959), luego reconocidas en la Convención de los Derechos del Niño (1989) ${ }^{\text {liv}}$, la cual dice en su Preámbulo: "el niño, por su falta de madurez física y mental, necesita protección y cuidado especiales, incluso la debida protección legal, tanto antes como después del nacimiento". En su Art. 6: Los Estados Partes reconocen que todo niño tiene el derecho intrínseco a la vida. Esta Convención fue ratificada en la República Argentina, ergo, es un Estado Parte. La ley Argentina expresa claramente que se considera niño desde la concepción hasta los 18 años. Doctrina que tiene valor constitucional -o supralegal $^{\mathrm{lv}}$-, la cual categóricamente se halla por sobre cualquier interpretación ambigua del Código Civil o Penal. Concretamente, en la Ratificación de la Convención de los Derechos del Niño (ley 23.849/90, Art. 20)" relación al art. 1으 de la Convención sobre los Derechos del Niño, la República Argentina declara que el mismo debe interpretarse que se entiende por niño todo ser humano desde el momento de su concepción y hasta los 18 años de edad". No especifica diferencias de etapa, edad, si fue planeado o no, si es sano, enfermo o si la fusión sexual que lo originó era consentida o no.

\section{Corte Suprema, ¿violación o careta?}

El daño provocado por violencia sexual es inconmensurable. La Corte Suprema de Justicia de la Nación Argentina (CSJN), -máxima autoridad para aplicar el derecho de fondo y el derecho constitucional-, en marzo de $2012^{\text {lvii }}$, considera que no existe conflicto de derechos entre la persona por nacer -inocente del atentado sufrido por la mujer- y quien resultó embarazada por una violación, ni que exista una protección absoluta del derecho a la vida del nasciturus, ni que sea inconstitucional abortar en estos casos. Entonces, la CSJN, pragmáticamente, falla que si una mujer dice estar embarazada tras una violación, el Estado debe practicarle un aborto sin que para ello sea necesaria una denuncia, ni prueba; solo cumplirá con firmar una declaración sobre esto al médico.

\footnotetext{
- Klein L. 2005. ibíd. .pág. 305

- Junto con los tratados internacionales con jerarquía constitucional, la Constitución Nacional es la ley suprema de la Nación. Por ello que todas las demás normas deben adecuarse a ella, según lo establece su Artículo 31․ Orden Jerárquico: la Constitución Nacional rigen: $1^{0}$ Los Tratados Internacionales sin jerarquía constitucional de carácter supralegal (por encima de la Ley). $2^{\circ}$ La Ley. $3^{\circ}$ Los Decretos del Poder Ejecutivo. Por último, la Sentencia Judicial.
} 


\section{Ravista de la}

de la Universidad Nacional del Nordeste

Pero, aunque, la CSJN señale que mentir la declaración resulte un ilícito penal, sabemos que en este país, históricamente, se miente impune y arbitrariamente, y en todos los estamentos. Aquí, donde existe una idiosincrasia subliminal emblematizada en el tango Cambalache, pregunto: ¿Son pocos los que falsean para "zafar"? ¿Serán tan, tan excepcionales -como supone la Corte- los que ante una contrariedad sexual mientan y declaren juradamente en un formulario "ad oc"? ¿Cómo se defiende el humano prenatal de los efectos de esa mentira?

\section{Derechos Humanos: El aprieto del aborto}

Se denuncia al Estado por abandonar a la mujer en el aborto insalubre, lo cual viola numerosos Derechos Humanos garantizados por tratados internacionales incorporados en nuestra Constitución Nacional: Derecho a la vida, Derecho a la integridad, Derecho a la igualdad, Derecho a la libertad, Derecho a vivir una vida sin violencia, Derecho a la salud, Derecho a no sufrir discriminación. Pero apelar a los Derechos humanos implica decir que abortar no ataca la vida. Los Derechos Humanos no tienen sexo y edad. Contra el aborto legal se oponen las evidencias de las características indudablemente humanas del embrión* como pruebas concluyentes de su dignidad y su derecho a la vida. Por ende, -al mirar desde la evolución del pensamiento y la doctrina de los Derechos Humanos- eliminar una vida humana resulta inadmisible. Toda la lista completa de los Derechos Humanos antedicha, se puede aplicar -tal cual- a favor de los derechos del humano prenatal, y en contra la potestad de abortarlos."

\section{¿Penalizar siempre obliga?}

Pese al plexo legal, existe un concepto que indica que los fundamentos morales no son fácilmente traducidos a políticas públicas. En coincidencia con Nelson (1988) ${ }^{\text {lix }}$ existe el deber de cuidar la vida humana en gestación. Sin embargo, muy distinto es lograr que esta obligación ética se haga cumplir con el poder coercitivo de la ley.

Respetar al humano prenatal es una decisión íntima, ética y moral en la cual no hay modo "estatal" de imponer sobre la conciencia de cada mujer. Pero atención, de igual modo, el concepto de libertad en una sociedad democrática no obliga al Estado a ser socio con cualquier acto en contrario de la protección del embrión. Tampoco puede desentenderse de tantas acciones en su contra.

\section{¿Valentía por ley?}

¿Se puede exigir heroísmo y abnegación a toda mujer cuando el embarazo fue impuesto con violencia, o cuando la vida de la gestante corre un grave peligro, o el feto tiene una enfermedad mortal de tal modo que interrumpir su gestación "no empeora la suerte fatal del nasciturus" ?" . Cuando una grave y extraordinaria dificultad hiciera que continuar el

\footnotetext{
* Academia Nacional de Medicina "el niño por nacer, científica y biológicamente, es un ser humano cuya existencia comienza en el momento de la concepción".

• Klein L. ibid. pág 270
} 
embarazo sea una "excesiva exigencia", en esa situación, la mujer que decide abortar, no debería ser penada. (Stith, 2004).

\section{¿Ayuda condenar?}

La penalización del aborto no demuestra ser el camino que siempre logre una conducta de respeto al humano prenatal. Si se despenalizara ¿cambiaría o no el volumen de la práctica de lo que hoy ocurre? Difícil saberlo, existen datos muy dispares; quizás, como beneficio, reduciría la estigmatización aludida, facilitaría la consulta previa de la mujer, y con ello una adecuada y cuidadosa consejería para una decisión a plena conciencia de las reales posibilidades de llevar adelante el embarazo y el hijo o considerar la alternativa de la adopción.

\section{No es lo mismo Despenalizar que Legalizar el aborto.}

Despenalizar es quitar el castigo a una conducta antes condenada en el Código Penal.

Legalizar el aborto "libre" y gratuito, implica legitimar el derecho a exigir los recursos humanos y materiales del Estado para abortar. Ergo, legalizar implica revertir las leyes existentes de protección al humano prenatal, con el objeto de ofrecer la interrupción de esa vida dentro de la prestación de servicios, públicos o privados. Así, de lo que se puede por imposición de la fuerza, se pasa a lo legítimo. La ley permitiría ejercer un derecho subjetivo que cualquiera puede exigirlo -aún sin motivo- y que el Estado no puede negar.

\section{¿El Estado a quién ampara?}

El Estado es un proyecto de vida en común, un propósito de convivencialxi. Media su arbitraje o coacción para que los enfrentados no se destruyan unos a otros, para que no trituren a los más débiles ${ }^{x i i}$. Tanto, debe ser observador y regulador del uso del poder del fuerte, como proteger el derecho y la vida del más débil. Ahora bien, ¿̇el Estado tiene la obligación ética de ser un socio patrocinante de la decisión discrecional de interrumpir la vida de un humano en gestación?

Si la posición "aborto libre y legal" lucha por priorizar la decisión más privada de la mujer, en ese caso, el Estado ¿debería tomar partido por ella y ofertar cándidamente sus recursos en detrimento del humano prenatal? Si ocurriera de ese modo, eliminar una vida humana a petición ajena, parecería un acto médico normal.

\section{¿Qué se dice cuando se dice vida?}

Habida cuenta de tanta dialéctica en cada artículo sobre el aborto y que todos emplean la palabra vida, ¿qué se dice cuando se dice vida? Desde mi convicción: la Vida Humana es la oportunidad de participar del devenir de lo que existe y de lo que aún falta hacer, fundado en el potencial del humano para ser, crecer y desarrollarse desde su concepción.

\section{Reflexión de conclusión}

Al inicio señalaba el recurrente comportamiento de intentar dominar al Otro, particularmente descalificando su estatus moral. Hoy existe una continuidad histórica en la decisión de sub-humanizar al humano prenatal. Quien ejerza un poder podrá anularlo, negándole su oportunidad para acceder y participar en la vida. No obstante, atento a lo que ocurre, resumo que:

- La prohibición y el castigo demostraron que no disuaden. La mujer que decide abortar, lo hace sin dificultad, porque tiene el poder para hacerlo, es accesible y descriminalizado. Por 


\section{Revista de la
Facultad de Medicina}

de la Universidad Nacional del Nordeste

- lo tanto, mantenerlo punible solo entorpece la posibilidad de un asesoramiento oportuno que adecuadamente realizados, pueden llegar a salvar más vidas que castigando. Deben ser diferentes las maneras de lograr el respeto al humano prenatal.

- Uruguay aunque reconoce su fracaso en educación, redujo la Mortalidad proveyendo abortos medicamentosos y asesoramiento con el Estado. Sin embargo, Chile (con 17,5

- millones de habitantes, 2012), ha conseguido una muy buena reducción de la mortalidad sin legalizar el aborto, pero lo que sí ha hecho es trabajar vivamente por cinco décadas con toda su población en el progreso de las condiciones educativas, sociales, laborales, sanitarias y la correcta provisión de planificación familiar que reduce el embarazo no intencionado. En la Argentina (población de 42 millones) -aún con muchas faltas y requerimientos educativos, con índices sociales, de pobreza, marginación y aislamiento disimulados- la legalización del aborto con una laxa provisión por el Estado, no parece ser "la solución". Por el contrario, las condiciones prevalecientes acrecientan las causas del aborto.

- Quien atiende exclusivamente a la idea libre disposición del propio cuerpo, omite que en cada aborto siempre se suprime al humano prenatal —el cual es una realidad genética autocomandada que depende absolutamente de la gestante y solo ella puede asegurar su vida-. Ante esto, es imprescindible tener presente que absolutamente todas las personas hemos transcurrido por una vida prenatal y nos concedieron la oportunidad de nacer, hayamos sido deseados o no, planificados o no, oportunos o inoportunos, convenientes o inconvenientes. Y si bien, ya no es fácil averiguar si nosotros mismos fuimos previstos o no; mucho más difícil, quizá imposible, será saber si cada una de las respectivas e imprescindibles fusiones sexuales que originaron a nuestros ancestros $y$, que ahora dan lugar nuestra existencia, fue buscada, consentida o forzada. La vida acontece y sin permiso. Otro sería este mundo, y no sé si mejor, si solo sobrevivieran al aborto, las personas programadas por sus progenitores.

- Tanto, alistarse en la legalización el aborto para elevarlo como trofeo que quiebre el brazo patriarcal de una iglesia dogmática ${ }^{\mid x i i i}$, como decir fanáticamente, que el aborto es el "asesinato de un niño", genera un encierro y estallido belicoso que anula todo el diálogo y comprensión que amerita este problema. Y como se sabe, toda guerra, solo amplía la infinita estupidez humana.

- Aún así, el análisis es más complejo todavía, porque, tanto la aceptación del respeto al Otro, como emprender el compromiso vitalicio de un hijo, son hoy, virtudes en crisis, y para el desarrollo de ambas, quizás, mejor que la imposición, sea una educación y comportamientos ejemplares como incentivos para que el camino del respeto y el compromiso sea una celebración.

- La comunidad humana, a través de todas sus capacidades, debe seguir buscando los medios apropiados de proteger vida en todas sus formas: del humano prenatal y la de la mujer gestante. 


\section{REFERENCIAS CITADAS}

(') Bergman, S. Celebrar la diferencia. Ed. B. Bs. As. 2009. p.45

(ii) Millet Kate . Política sexual. Citado por Ana de Miguel Álvarez en LO PERSONAL ES POLÍTICO. Universidad de La Coruña P. ESCARIO, I. ALBERDI. A. LÓPEZ-ACOTO, Madrid, Instituto de la Mujer, Cátedra, 1996. En línea. http://e-spacio.uned.es:8080/fedora/get/bibliuned:filopoli1997-9-1111/pdf.

(iii) Historia de Vascos. Novoa Santos, R. La Federación Republicana Gallega. La Constitución de 1931. Madrid: Iustel. pp. 242-243. ISBN 978-84-9890-083-5. En línea. <http://m.deia.com/2013/11/02/sociedad/historias-de-los-vascos/papeletas-con-genero>

( ${ }^{\text {iv }}$ ) Chapman E., Pinzón C. La violencia doméstica en el embarazo y su relación con la muerte materna. Evidencias para su abordaje. El Observatorio de Salud Sexual y Reproductiva. No $^{\circ}$ Marzo 2014. En línea: http://www.ossyr.org.ar/pdf/hojas informativas/hoja 9.pdf

( ${ }^{\mathrm{v}}$ ) El Vaticano del Holocausto. 16/02/2003. En línea. http://news.bbc.co.uk/hi/spanish/misc/newsid_2766000/2766277.stm

(vi) Klein, L. Fornicar y matar, el problema del aborto. Planeta Bs. As. 2005

(iii)Selgelid M.J., ¿El aborto para la Prevención de las Imperfecciones Humanas? Aborto eugenésico, incertidumbres morales y consecuencias sociales Revista de Filosofía, ${ }^{\circ}$ 31, 2004, 115-130 p 118 y sigu..

(viii ) Savater |F. Espada A.http://www.elmundo.es/suplementos/magazine/2009/486/1232366706.html

$\left({ }^{\mathrm{ix}}\right)$ Tapía R. La formación de la persona desde el punto de vista de la Neurobiología. En línea. <http://colegiodebioetica.org.mx/wp/wp-content/uploads/2011/12/rtapia-001.pdf www.inb.unam.mx/bioetica/.../rtapia_ab_neuro_355apersona.pdf >

( $\left.{ }^{x}\right)$ Di Pietro J.A. Consideraciones psicológicas y psicofisiológicas sobre la relación materno-fetal. Desarrollo infantil, Número especial: hacia una psicología fetal Volumen 19 , Número 1 , Enero / Febrero 2010 En línea http://onlinelibrary.wiley.com/doi/10.1002/icd.651/abstract

${ }^{\left({ }^{x i}\right)}$ Bellieni, CV. Evaluación del dolor en el feto humano y bebés AAPS J ; 14 (3) :456-61, septiembre 2012 En línea. <http://www.ncbi.nlm.nih.gov/pmc/articles/PMC3385812/?tool=pubmed

${ }^{\left({ }^{x i i}\right)}$ García Heller, T . M. Principales Aportaciones acerca del Desarrollo Psíquico Intrauterino. En línea. Disponible en: <www.tesis.uchile.cl/tesis/uchile/2007/garcia_t/sources/garcia_t.pdf >

(xiii $)$ Memoria en el útero. En línea. <http://entzumena.wordpress.com/2013/11/23/memoriaintrauterina/

${ }^{\text {xiv }}$ ) Barylko, Jaime. El miedo a los hijos. Bs. As. Emecé. 1992 p.172 y sigu.

${ }^{\left({ }^{x v}\right) M a n e s, ~ F . ~ N i r o, ~ M . ~ U s a r ~ e l ~ c e r e b r o . ~ 8 º ~ . ~ e d . ~ B s . ~ A s . ~ P l a n e t a ~ . ~ 2014 . ~ p a ́ g . ~} 25$ y sigu.

$\left.{ }^{(x v i}\right)$ Rosler, Roberto. Disertación en la Facultad de Medicina de la UNNE. 17-06-2014

$\left({ }^{\text {xvii }}\right)$ Wertheimer, Roger “Comprender la discusión sobre el aborto”. En Debate sobre el aborto: cinco ensayos de filosofía moral. E. Teorema. Madrid. 1983. 
$\left({ }^{\text {xviii }}\right)$ Reid, M. Gillett, G. Universidad de Otago Medical School, de Nueva Zelanda El caso de Medea una visión del conflicto materno-fetal Journal ética of medical, 1995

${ }^{\left({ }^{\mathrm{xix}}\right)}$ Stith , Richard. En base a su dignidad humana Revista Chilena de Derecho, Vol.21 № 2,pp. 359361 (1994) Original publicado en The Human Life Review, Vol. XIX,№ 3. Summer 1993. En línea. <http://www.bioeticaweb.com/index2.php?option=com_content\&do_pdf=1\&id=256 >

( $\left.{ }^{\mathrm{x}}\right)$ Macklin R. La dignidad es un concepto inútil. BMJ. 200320 de diciembre; 327 (7429): 14191420. doi: 10.1136 / bmj.327.7429.1419. En línea: http://www.ncbi.nlm.nih.gov/pmc/articles/PMC300789/

$\left({ }^{\text {xxi }}\right)$ Pyrrho, M Cornelli, G Garrafa V. Dignidad humana. Reconocimiento y operacionalización del concepto. Acta bioeth. v.15 n.1 Santiago 2009. En línea. http://dx.doi.org/10.4067/S1726569X2009000100008

${ }^{\left({ }^{x i i}\right)}$ Enciclopedia Britannica agitprop (historia soviética) Agit - prop En línea: $<$ http://www.britannica.com/EBchecked/topic/9224/agitprop

( ${ }^{\text {xiii) }}$ Cavallo, M. Inaccesibilidad al aborto no punible en la Argentina: obstáculos de IURE y obstáculos de FACTO. En CUESTIÓN de DERECHOS № 1, Julio de $2011 \mathrm{R}$ e $\mathrm{v}$ i s $\mathrm{t}$ a e l e c $\mathrm{r}$ ó $\mathrm{n}$ i c a Buenos Aires, Argentina. Publicación semestral de la Asociación por los Derechos Civiles Dossier: Despenalización del aborto voluntario. En línea http://www.cuestiondederechos.org.ar/pdf/numero1/05-inaccesibilidad-al-aborto-nopunible-Mercedes-Cavallo.pdf

(xxiv) Mainetti, M. ¿Aborto legal para no morir? Revista Ciudad Nueva. № 475, pág. 15. Marzo, 2007.

$\left.{ }^{(x \times v}\right)$ Reyes Calderón J. A. (2012) Descriminalización y Despenalización Centro de Estudios Estratégicos y de Seguridad para Centroamérica (CEESC). 12-4-2012 En línea. <http://www.lahora.com.gt/index.php/nacional/guatemala/reportajes-y-entrevistas/156400descriminalizacion-y-despenalizacion

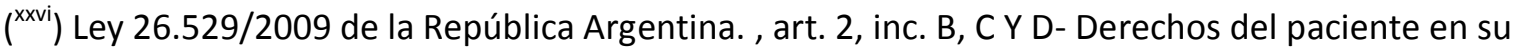
relación con los profesionales e instituciones de la salud. En línea http://www.hospitalposadas.gov.ar/docum/derechospaciente.pdf

( ${ }^{\text {xxvii }}$ Sentencia de Cámara Nacional de Apelaciones en lo Criminal y Correccional, 26 de Agosto de 1966 En línea. http://ar.vlex.com/vid/recurso-criminal-correcional-n-28-26-35220192

(35) La doctrina del “Plenario Frías” PRAXIS MEDICA - Asociación de Médicos municipales. Aborto: algunas reflexiones medico legales y jurídicas . AUTORES: Pini, M. Lossetti, O. Trezza,F. En línea. Disponible en: <http://www.medicos-municipales.org.ar/prax0406.htm\#1 > [consultado 21-6- 2014]

$\left({ }^{\text {xxix }}\right)$ "No cabe instruir sumario en contra de una mujer que ha causado su propio aborto o consentido que otro lo causara, sobre la base de una denuncia efectuada por un profesional del arte de curar...Sentencia de Cámara Nacional de Apelaciones en lo Criminal y Correccional, 26 de Agosto de 1966 


\section{0

$\left({ }^{\mathrm{xx}}\right)$ Estudio Nacional de Opinión Pública sobre "Derechos Sexuales, aborto y violencia sexual" en grandes centros urbanos (2006) cedes-unfpa En línea. $<$ www.despenalizacion.org.ar/pdf/.../Estudio_CEDES-UNFPA_2006.p

$\left({ }^{\mathrm{xxx}}\right)$ Encuesta R. Rouvier sobre la legalización del aborto En línea. http://www.rimaweb.com.ar/wpcontent/uploads/2010/07/gacetilla-aborto-07-04-rouvier-y-asociados.pdf

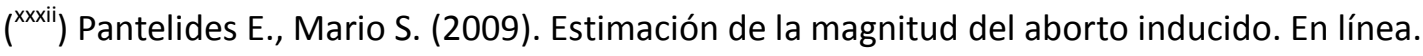
http://www.despenalizacion.org.ar/pdf/Evidencia/Estudios/Estimacion_aborto_inducido.pdf

( ${ }^{\text {xxxiii }}$ ) Koch. E. Sobrestimación del aborto inducido en Colombia y otros países Latinoamericanos Ginecol Obstet Mex 2012;80(5):360-372. En línea.

( ${ }^{\text {xxxiv }}$ ) Wilcox et al. El momento de las relaciones sexuales en relación con la ovulación - Efectos sobre la probabilidad de concepción, de la supervivencia del embarazo. N. Engl J Med 1995; 333:1517-1521. DOI: 10.1056/NEJM199512073332301. En línea. http://www.nejm.org/doi/full/10.1056/nejm199512073332301\#t=articleBackground.

${ }^{(x \times x v)}$ Koch. E., Bravo M., Gatica, S., Stecher, J. Aracena, P., Valenzuela, S. Sobrestimación del aborto inducido en Colombia y otros países Latinoamericanos Ginecol Obstet Mex 2012;80(5):360-372. En línea.

file://C:/Documents\%20and\%20Settings/Administrador/Escritorio/DOCUMENTOS\%20DEL\%20USUARIO\% 202/ETICA/WILCOX\%20\%20MOMENTO\%20DE\%20LA\%20RELACI\%C3\%93N\%20Y\%20POSIBILIDAD \%20DE\%20GESTACION.pdf

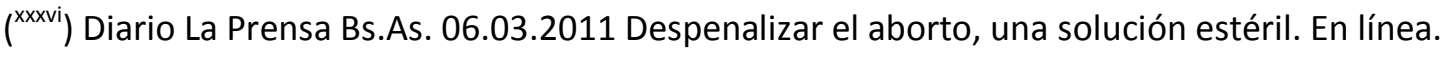
<http://www.laprensa.com.ar/372047-Despenalizar-el-aborto-una-solucion-esteril.note.aspx>

( ${ }^{\text {xxxvii }) ~ N a t h a n s o n ~ B . ~ E x t r a c t o ~ d e ~ c o n f e r e n c i a ~ e n ~ C a n b e r r a . ~ 1981 . ~ E n ~ l i ́ n e a . ~}$ http://foropelayo.blogcindario.com/2005/11/00202-la-conversion-cientifica-de-bernard-nathanson.html.

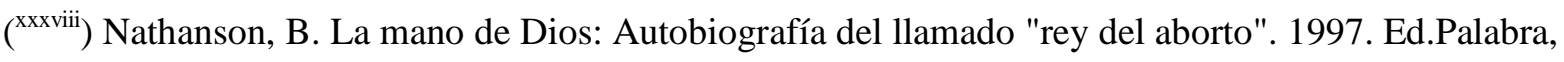
Madrid.

$\left({ }^{x x x i x}\right)$ Aborto en Uruguay, la excepción latinoamericana. En línea. http://sociedad.elpais.com/sociedad/2014/03/07/actualidad/1394208119_165255.htmlhttp:/ /www.republica.com.uy/en-uruguay-la-despenalizacion-no-genero-mas-abortos/

(") http://www.deis.gov.ar/publicaciones/archivos Datos años 2008, 2009, 2010, 2011, 2012 у 20

13 http://www.deis.gov.ar/Publicaciones/Archivos/Serie5Nro52.pdf. y series post. Mortalidad Materna según variables seleccionadas argentina - AÑO 1998-2007 Boletín Número 124ISSN 03014630

(xlii ) Observatorio de Femicidios en Argentina "Adriana M. Zambrano" Coord. Asoc. Civil La Casa del Encuentro. https://www.google.com.ar/webhp?sourceid=chromeinstant\&rlz=1C1DVCI_enAR430AR432\&ion=1\&espv=2\&ie=UTF8\#q=observatorio + de + femicidios + en + argentina +2013

( ${ }^{x \text { liii }) ~ M a y o r i ́ a ~ d e ~ l a s ~ m u j e r e s ~ q u e ~ a b o r t a n ~ f u e r o n ~ v i ́ c t i m a s ~ d e ~ v i o l e n c i a ~ c o n y u g a l . ~}$ http://www.lanacion.com.py/articulo/86685-mayoria-de-las-mujeres-que-abortan-fueronvictimas-de-violencia-conyugal.html 


\section{0

( ${ }^{\text {xliv}) ~ H a l l ~ M, ~ C h a p p e l l ~ L C, ~ P a r n e l l ~ B L, ~ S e e d ~ P T, ~ B e w l e y ~ S . ~ A s s o c i a t i o n s ~ b e t w e e n ~ i n t i m a t e ~ p a r t n e r ~}$ violence and termination of pregnancy: a systematic review and meta-analysis. PLoS Med. 2014 Jan;11(1):e1001581.

$\left({ }^{\mathrm{xlv}}\right.$ ) Collado Peña S, Villanueva Egan LA. [Domestic violence: an approach rom gynecology and obstetrics]. Ginecol Obstet Mex. 2005 ay;73(5):250-60. Review. Citado por Chapman y Pinzón

( ${ }^{\text {xlvi }}$ ) Shadigian E, Bauer ST. Pregnancy-associated death: a qualitative systematic review of homicide and suicide. Obstet Gynecol Surv. 2005 Mar;60(3):183-90. Citado por Chapman y Pinzón

( ${ }^{\text {xvii }}$ ) Aborto en Uruguay, la excepción latinoamericana http://sociedad.elpais.com/sociedad/2014/03/07/actualidad/1394208119_165255.html

( ${ }^{\text {xlviii }) ~ M u j i c a, ~ J . ~ E n t r e v i s t a ~ a ~ e n ~ T V E .(v i d e o g r a b a c i o ́ n . ~ m i n u t o ~ 14: 41) ~ E n ~ l i ́ n e a . ~}$ <http://www.youtube.com/watch?v=aaLCZ14qwF4

${ }^{\left({ }^{x l i x}\right)}$ Mujica, J. Para Mujica, "Problemas de la educación son por fracasos familiares" En línea. http://eldiario.com.uy/2013/12/03/para-mujica-problemas-de-la-educacion-son-por-fracasosfamiliares/

(') Estadísticas del primer año de aborto legal en Uruguay. En línea. <http://www.periodismo.com/2014/02/26/estadisticas-del-primer-ano-de-aborto-legal-enuruguay/

(") Chile reduce mortalidad materna con embarazo seguro y no con abortos. En línea en: <http://sscchistoria8vo.blogspot.com.ar/2010/05/chile-reduce-mortalidad-materna-con.html $>$ y <http://www.chile.com/secciones/ver_seccion/120588/chile-disminuye-mortalidadmaterna-sin-legalizar-el-aborto/>

(iii) Koch, E. La Educación es fundamental en la reducción de la mortalidad materna 22-03-2010.Pag web de la Fac. de Medicina de la Universidad de Chile. En linea http://www.med.uchile.cl/2010/marzo/4093-educacion-es-fundamental-en-la-reduccion-dela-mortalidad-materna-.html

(iii) Donoso S., E. y Oyarzún E., E. (2005)Mortalidad materna, Chile 2003: ¿Continúa el gran descenso? Rev. chil. obstet. ginecol. 2005, vol.70, n.2. En línea. http://www.scielo.cl/pdf/rchog/v70n2/art03.pdf

( ${ }^{\text {liv }}$ ) Convención sobre los Derechos del Niño. 20 de noviembre de 1989. En línea: http://www2.ohchr.org/spanish/law/crc.htm

( ${ }^{\text {IV }}$ Constitución Nacional - Argentina.gob.ar. Orden Jerárquico en relación a Constitución Nacional. En línea. Disponible en: <www.argentina.gob.ar/pais/63-constitucion-nacional.php

(vi) Ley 23.849/90 Sancionada: Setiembre 27 de 1990. Promulgada de hecho: Octubre 16 de 1990 Artículo 2을 En líea. http://www.trabajo.gov.ar/downloads/trabajoinfantilno/ley23849.pdf >

('vii ) La Corte Suprema precisó el alcance del aborto no punible y dijo que estos casos no deben ser judicializados http://www.cij.gov.ar/nota-8754-La-Corte-Suprema-preciso-el-alcance-del-aborto-nopunible-y-dijo-que-estos-casos-no-deben-ser-judicializados.html

('viii ) CENTRO DE INFORMACIÓN JUDICIAL: FALLO COMPLETO de la CSJN. http://www.cij.gov.ar/nota-8754 
${ }^{\left({ }^{l i x}\right)}$ Nelson M. El tratamiento médico Obligado de las mujeres embarazadas, la vida, la libertad y el derecho en conflicto. Diario de la American Medical Association. 1988; 259: 1061.

$\left({ }^{\mathrm{lx}}\right)$ Pronunciamiento de la Suprema Corte de Justicia de la Nación sobre anencefalia. En línea. $<$ http://www.medicos-municipales.org.ar/prax0406.htm\#1

$\left({ }^{\text {lxi }}\right)$ Ortega y Gasset, 1921 Cit. Llano Alonso, F. El estado y la idea orteguiana de nación. U. Sevilla. En línea http://portal.uned.es/pls/portal/docs/PAGE/UNED_MAIN/LAUNIVERSIDAD/UBICACIONE S/06/PUBLICACIONES/REVISTA\%20DIGITAL\%20FACULTAD\%20DE\%20DERECHO/N UMEROS\%20PUBLICADOS/NUMERO2/PRIMER\%20PREMIO.PDF

(1xii) Sabater F.Política para Amador. E. Ariel Bs As. 1993 pág 49.

(1xiii) Lamas, Marta. LAS FRONTERAS DEL DERECHO A DECIDIR. (2007) En línea. <http://www.chasque.net/frontpage/comision/dossieraborto/cap8_2.htm

\section{Datos de autor}

\section{ROBERTO A. SOSA TROTTI}

*Médico. Instructor del Internado de Obstetricia. Facultad de Medicina. U.N.N.E.

Moreno 1030. Corrientes. Rep. Argentina

Jefe de Servicio de Extensión a la Comunidad del Hospital "Dr. J.R. Vidal”. Corrientes.

E-mail: rolisosatrotti @yahoo.com.ar

Título abreviado: El problema del aborto 